\title{
Equilibrium and Kinetic Study of Removal Copper(II) from Aqueous Solution Using Chicken Eggshells: Low-Cost Sorbent
}

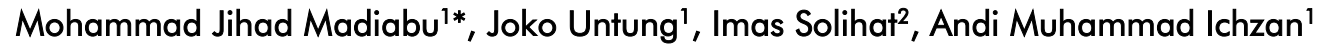 \\ 'Department of Analytical Chemistry, Politeknik AKA Bogor, Indonesia \\ ${ }^{2}$ Department of Food Quality Assurance, Politeknik AKA Bogor, Indonesia \\ *Corresponding author email: mijhad1991@gmail.com
}

Received May 10, 2020; Accepted February 23, 2021 ; Available online March 25, 2021

\begin{abstract}
The research aims to investigate feasibility eggshells as potential adsorbent for copper (II) ion removal from an aqueous solution. The eggshells powder was characterized using X-ray diffraction, scanning electron microscopy, and Fourier transform infrared spectroscopy. The effect of copper (II) initial concentration, adsorbent dosage, and contact were have conducted to determine the optimum adsorption process. The maximum percentage of copper(II) removal was exceeded more than 85\%. The Langmuir, Freundlich, and Dubinin-Radushkevich isotherm model were applied to describe its equilibrium adsorption. The copper (II) kinetics sorption process was fitted to pseudo-second order model with a rate constant equal to $0.516 \mathrm{~g} / \mathrm{mg}$.min. The results clearly exhibit that eggshells powder can be effectively used to remove copper(II) ions from aqueous solutions.
\end{abstract}

Keywords: adsorption, eggshells, isotherm adsorption, kinetic

\section{INTRODUCTION}

Industrial waste water is commonly containing many heavy metals, such as iron, copper (II) and chromium (Yeddou and Bensmaili, 2007). Heavy metals are toxic, non-degradable, have high mobility in water, and tend to accumulate in living organism (Yeddou and Bensmaili, 2007; Ahmad, Usman, Lee, Kim, \& Joo, 2012). Wastewater is hazardous for human health. It was reported that many diseased are related to the heavy metal's pollution in water. Copper (II) is commonly generated from mining operation, tanneries, metals manufacturing, electroplating, batteries and electronics industry (Borhade and Kale, 2017). Copper (II) could cause the heart attack, carcinogenic, and make some mental issues when consumed over the lethal doses (Afroze and Sen, 2018). According to regulation from Indonesia State Ministry of Environment Number 5 (2014), the upper limit for copper (II) ions in industrial wastewater is 2 $\mathrm{mg} / \mathrm{L}$. Therefore, the industrial wastewater must be treated to ensure the copper (II) concentration is below the allowed limits before being discharges to environment.

Heavy metals removal in aquatic system become challenging issues for researcher. The heavy metals can be removed from water by using some various methods, such as ultrafiltration, coagulation, electrolysis, and reverse osmosis. However, the need for additional chemicals makes these methods less effective and possibly causes new problems with the formation of other toxic compounds. Besides, high initial cost and complicated procedure are required (Alemayehu and Lennartz, 2010; Bade and Lee, 2011; Fu and Wang, 2011). Among all these methods, adsorption is an effective method to remove heavy metals from water compared the methods above in term of its simplicity and less possibility to produce a toxic by product.

Activated carbon is common adsorbent for heavy metals removal. It has internal pore structure extensively and also high crystallinity. However, since it is used coal as the main precursors and required complicated methods for synthesized, commercially available activated carbon still considered as an expensive material. Therefore, in recent years, the main focus of the researchers is to develop low-cost alternative materials to treat heavy metals in aquatic system, and one of the possible ways is by regenerated a natural waste (Park, Jeong, Yang, Kim, \& Lee, 2007; Ahmad et al., 2012; Simate, \& Ndlovu, (2014). The utilization of natural waste as adsorbent is preferred because of its abundance, low cost and possess porous structure (Bhatnagar, Minocha, \& Sillanpaa, 2010). One of the potential natural waste material adsorbents is eggshells.

Chicken egg is food commodity which widely consumed in Indonesia. According to data from the Ministry of Agriculture, total production of chicken egg was 1.64 million in 2018 and predicted to increase in the upcoming years. The eggshell weight is 
approximately $11 \%$ from total weight of egg. The eggshells wastes left in large quantity from food manufacturing unit, restaurants, bakeries, and homes. The most of eggshells is commonly disposed in landfill without any pretreatment. They will generate some problem such as unpleasant odor and medium for bacterial growth. Eggshells usually treat as waste, even though it possesses high potency for some application.

The eggshells contain high nutrient content such as calcium, phosphorus, and magnesium. Because of that, it can be reused and applied as a fertilizer and feed additive (Carvalho, Araujo, \& Castro, 2011). The chemical composition of eggshells is $94 \%$ calcium carbonate, $1 \%$ calcium phosphate, $1 \%$ magnesium carbonate and $4 \%$ organic compound that have carbonyl, carboxyl, and amine group (Eletta, Ajayi, Ogunleye, \& Akpan, 2016). Based on that, eggshells can be applied as heavy metals adsorbent, acid neutralizer in soil, and production of hydroxypatite (Liao et al., 2010; Setiawan, Rizqi, Brilianti, \& Wasito, 2018). The porous surface in eggshells provide a large surface area that can be utilized as an alternative catalyst and adsorbent (Ahmad et al, 2012; Gollakota, Volli, \& Shu, 2019; Oliveira, Benelli, \& Amante, 2013). Various heavy metals adsorption using eggshells has been done before, such as $\mathrm{Pb}(\mathrm{II})$, $\mathrm{Cu}$ (II), Ni(II) and Cd(III) (Ahmad et al, 2012; Kristianto, Daulay, \& Arie, 2019; Tizo et al., 2018). Therefore, eggshell is one promising material to remove heavy metals from the aquatic system.

The eggshell adsorption capacity can be boost up by treating the eggshell prior to use. In recent years, physical activation such as calcination is widely known process that able to improve the eggshell adsorption capacity. Kristianto et al., (2019) reported that calcined eggshell can increase the adsorption capacity to 60 times. In fact, as our knowledge, the chemical activation process using alkaline solution is rarely investigated.

The objective of this research is the utilization the eggshells for low-cost adsorbent material to remove copper (II) from artificial waste water. Eggshells adsorbent was chemically activated by an alkaline solution. The effect of some parameters such as adsorbate concentration, contact time, and mass of adsorbent were studied and discussed detail in the following section. The equilibrium adsorption process was investigated by Freundlich, Langmuir, and Dubinin-Radushkevich adsorption isotherm model. Adsorption kinetic was examined by fitting the experimental data to some kinetic model, i.e. pseudofirst order and pseudo-second order.

\section{EXPERIMENTAL SECTION}

\section{Preparation of Eggshells Adsorbent}

Eggshells were collected from local restaurants in Tanah Baru Sector, North Bogor, Bogor. Eggshells were cleaned and rinsed several times by using distilled water. Then, the cleaned eggshells were added to potassium hydroxide $0.1 \mathrm{~mol} / \mathrm{L}$ solution and stirred for 1 hour. After that, the mixture was filtered and washed with distilled water until $\mathrm{pH} 6$ to 7 , followed by drying in the oven at $100^{\circ} \mathrm{C}$ for 24 hours. The dried eggshells then grinded and sieved well in 60 mesh particle size

\section{Characterization}

Fourier Transform Infrared (FT-IR) was performed in the range of $500-4000 \mathrm{~cm}^{-1}$ to confirm the qualitative analysis organic functional group in eggshells. X-Ray Diffraction (Shimadzu X-Ray Diffractometer 7000 Maxima-X) with $C u$ tube and scan rate $2.00 \mathrm{deg} / \mathrm{min}$ was used to confirm the phase purity of sample, and finally surface morphology eggshells powder was investigated by using scanning electron microscope (SEM).

\section{Batch Adsorption Experiment}

The effect of some parameters such as adsorbate concentration, contact time, and adsorbent dosage were studied. A definite weight of eggshell powder was added into $100 \mathrm{~mL}$ of copper (II) solution with various initial concentration between $10 \mathrm{mg} / \mathrm{L}$ to $150 \mathrm{mg} / \mathrm{L}$. Copper (II) solution was prepared from $1000 \mathrm{mg} / \mathrm{L}$ stock solution. The contents were shaken during certain time following with filtration of the solution. Residual copper (II) ion in solution was measured using atomic absorption spectrophotometer. The amount of copper (II) metal adsorbed was calculated using Eqs 1.

$$
q_{\mathrm{e}}=\left(\left(C_{0}-C_{e}\right) \cdot V\right) / w
$$

where, $q_{e}$ is the amount of copper(II) adsorbed per gram eggshell powder $(\mathrm{mg} / \mathrm{g}), C_{0}$ is the initial concentration of copper (II) ion (mg/L), $C_{e}$ is the concentration of copper (II) ion in equilibrium state $(\mathrm{mg} / \mathrm{L}) . V$ represents the volume of copper (II) solution $(\mathrm{L})$, and $w$ is the mass of eggshell powder (g). The results were verified with Langmuir, Freundlich, and Dubinin-Radushkevich adsorption isotherm model, while the kinetic study was investigated with pseudofirst order and pseudo-second order.

\section{RESULTS AND DISCUSSION Characterization of Eggshells Powder FT-IR Spectroscopy}

The FT-IR spectrum of eggshells powder was analyzed on Bruker, Platinum ATR spectrometer in the range $4000-500 \mathrm{~cm}^{-1}$ and the result was depicted in Figure 1. The peak between $700 \mathrm{~cm}^{-1}$ to $863 \mathrm{~cm}^{-1}$ showed the in-plane and out-plane vibration mode of calcium carbonate (Kristianto et al., 2019; Tsai et al., 2006; Ahmad et al., 2012). The sharp peak at $1406.97 \mathrm{~cm}^{-1}$ denoted to $\mathrm{C}=\mathrm{O}$ asymmetrical stretching vibration on carbonate compound in eggshells matrix. Weak broad peak at $3263.31 \mathrm{~cm}^{-1}$ was formed. This peak related to $-\mathrm{OH}$ functional group stretching vibration due to the existence of free hydroxyl group which adhere in adsorbent surface (Daraei, Mittal, Noorisepehr, \& Mittal, 2015). 


\section{X-Ray Diffraction}

X-Ray diffraction pattern of eggshells crystal structure was examined using Shimadzu X-Ray Diffractometer 7000 Maxima- $X$ and its result is showed in Figure 2. Main peak was appeared in $2 \theta=$ $29.5^{\circ}$ which indicated calcium carbonate as major

component of eggshells (Park et al., 2007; Ahmad et al., 2012). Moreover, several peaks appeared at $2 \theta=$ $23.1^{\circ} ; 29.2^{\circ} ; 29.5^{\circ} ; 36.0^{\circ} ; 39.5^{\circ} ; 43.2^{\circ} ; 47.6^{\circ} ; 48.6^{\circ}$; $57.5^{\circ} ; 64.8^{\circ}$. This diffraction pattern well matches with JCPDS file (card no 05-0586).

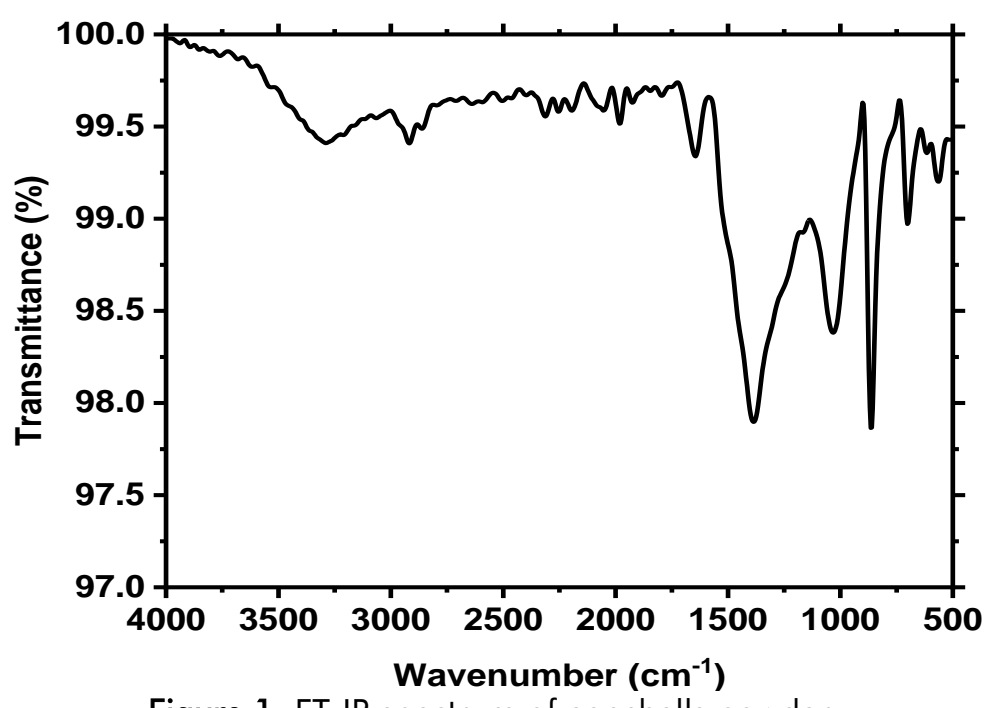

Figure 1. FT-IR spectrum of eggshells powder.

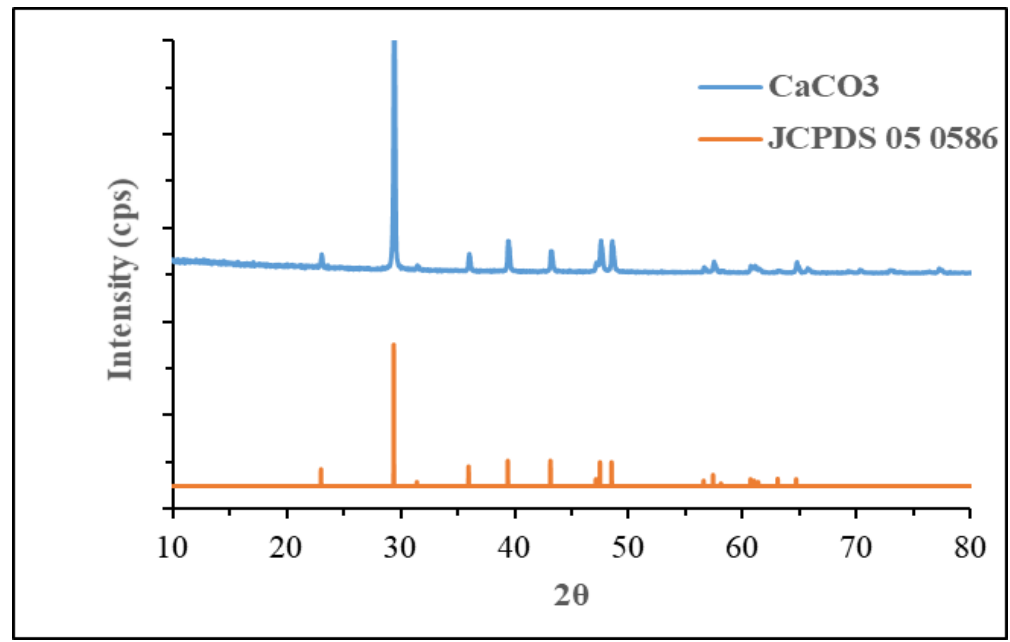

Figure 2. X-Ray diffraction patern of eggshells powder.
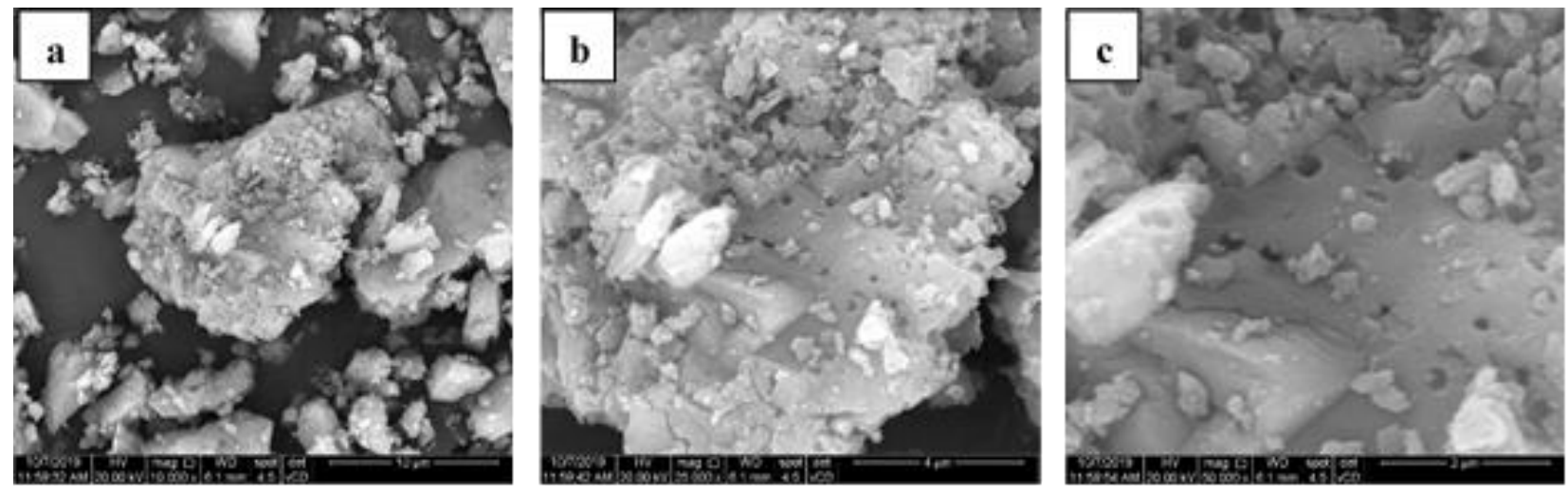

Figure 3. SEM images of eggshells powder, (a) 10.000 times magnification, (b) 25.000 times magnification, (c) 50.000 times magnification. 


\section{Surface Morphology}

Surface morphology of eggshells was characterized by scanning microscope electron and the result is denoted in Figure 3. SEM images exhibited a clear view to observe surface morphology. At 10000 times magnification showed that eggshells powder had agglomerated prismatic shapes particles and at 25000 times magnification exhibited that the surface of eggshells was mainly porous (Park et al., 2007). In further magnification (50000 times), porous in the surface was clearly showed. It has a diameter ranging $0.1 \mu \mathrm{m}$ to $0.3 \mu \mathrm{m}$. Therefore, eggshells porous has a microporous size (Setiawan et al., 2018)

\section{Adsorption process}

\section{Effect of adsorbent dosage}

In this study, adsorbent dosage was varied from $0.1 \mathrm{~g}$ to $1.1 \mathrm{~g}$, while copper (II) ion concentration was constant for all dosage with 50 minutes of contact time. Figure 4 shows the effect of adsorbent dosage on adsorption copper (II) ion by eggshells powder. The percentage adsorption efficiency process increased slowly from $0.1 \mathrm{~g}$ to $0.7 \mathrm{~g}$ from $62.4 \%$ to $91.7 \%$. However, when the maximum adsorption capacity is achieved, additional adsorbent dosage became insignificant in copper (II) removal capacity. This trend caused by agglomerated eggshells particles, so the active sites in eggshells surface is reduced and increased the adsorbate diffusion path length (Semeriian, 2018).

\section{Effect of adsorbate initial concentration}

Concentration is a prominent factor in the adsorption process. The effect of copper(II) ion initial concentration was carried out by using optimum adsorbent dosage and 50 minutes of contact time. The initial concentration was varied from $10 \mathrm{mg} / \mathrm{L}$ to 150 $\mathrm{mg} / \mathrm{L}$. The percentage of adsorption efficiency process was denoted in Figure 5. It exhibited the adsorption

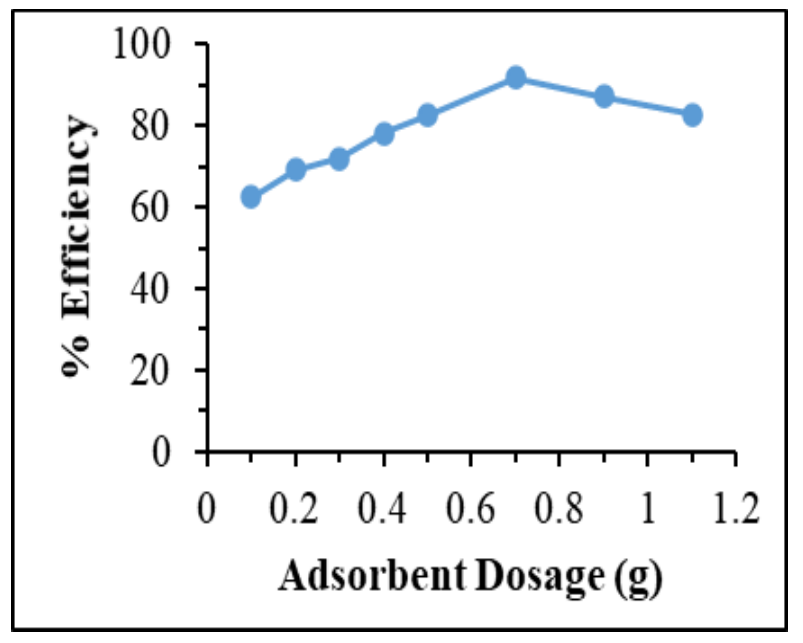

Figure 4. Plot of adsorption copper (II) ion by eggshells powder with variation of adsorbent dosage process in the low concentration occurred rapidly. The maximum percentage of efficiency of removal was $91.25 \%$ at $50 \mathrm{mg} / \mathrm{t}$.

The high percentage of adsorption efficiency indicated that mass transfer diffusion of copper (II) ions from bulk goes rapidly to eggshells surface (Subbareddy, Jeseentharani, Jayakumar, Nagaraja, \& Jeyarai, 2012). Fürther, with increasing the concentration, the percentage of adsorption efficiency slightly decrease. At higher concentration, copper (II) ions diffused to eggshells surface followed by intra particle diffusion model (Afroze, \& Sen, 2018). Surface active sites saturated rapidly with copper (II) ions in the initial adsorption process. However, after that, adsorption process occurred slowly due to competition between copper (II) ions to attach in eggshells surface.

\section{Effect of contact time}

Contact time is a significant factor in the adsorption process. In this study, contact time was varied from 10 minutes to 110 minutes, while copper (II) ion initial concentration and eggshells dose were constant. The parameter was used to calculate the rate of adsorption process. The adsorption efficiency increased from $61.6 \%$ to $89.2 \%$ at $10-30$ minutes of contact time. In the beginning, a rapid adsorption rate was observed due to highly available vacant active sites (Tang, Li, Wang, \& Daroch, 2017). The maximum copper (II) adsorption efficiency was $91.5 \%$ at a contact time of 50 minutes. At that time, the adsorption equilibrium reached. It indicated that the active sites already saturated with copper (II) ions. Further, increase in contact time, the concentration of copper (II) ions in eggshells surface increasing gradually but make no significant effect on the copper (II) ions removal due to intra particles diffusion rate into bulk adsorbent was gone slowly.

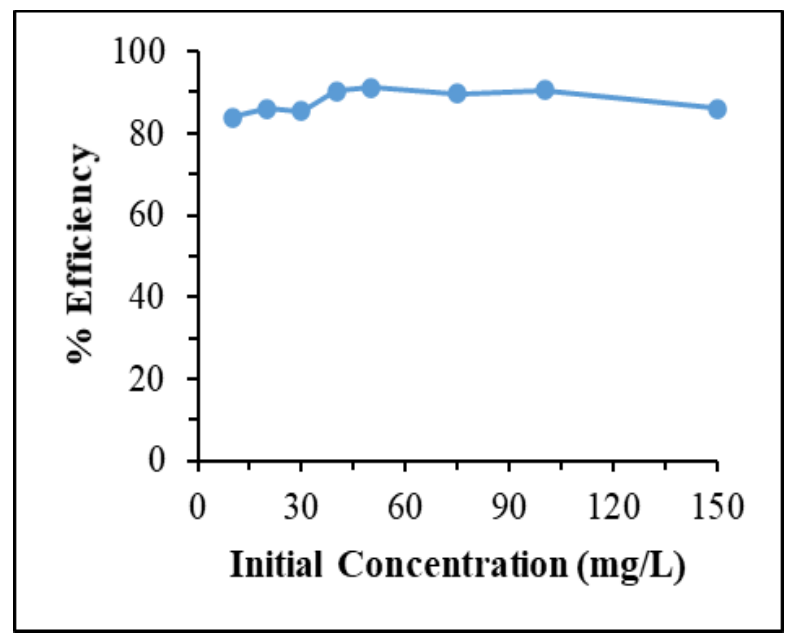

Figure 5. Plot of adsorption copper (II) ion by eggshells powder with variation of adsorbate initial concentration. 


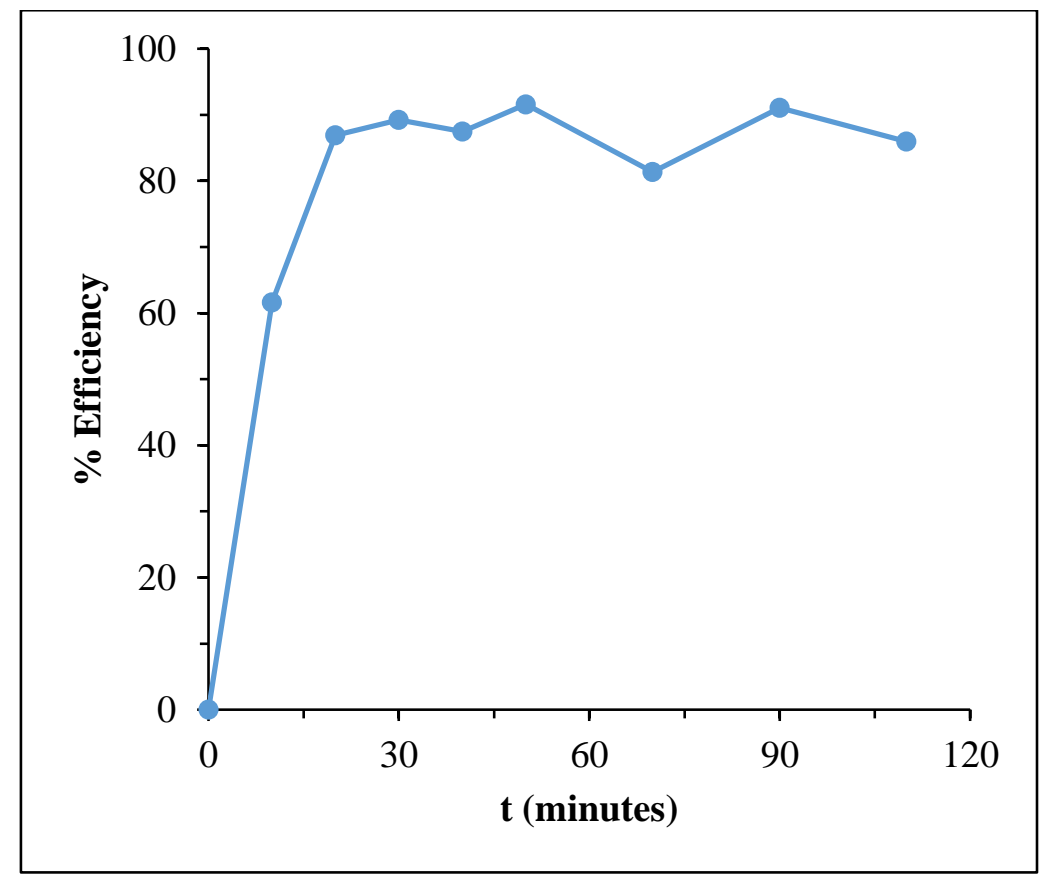

Figure 6. Plot of adsorption copper (II) ion by eggshells powder with variation of contact time
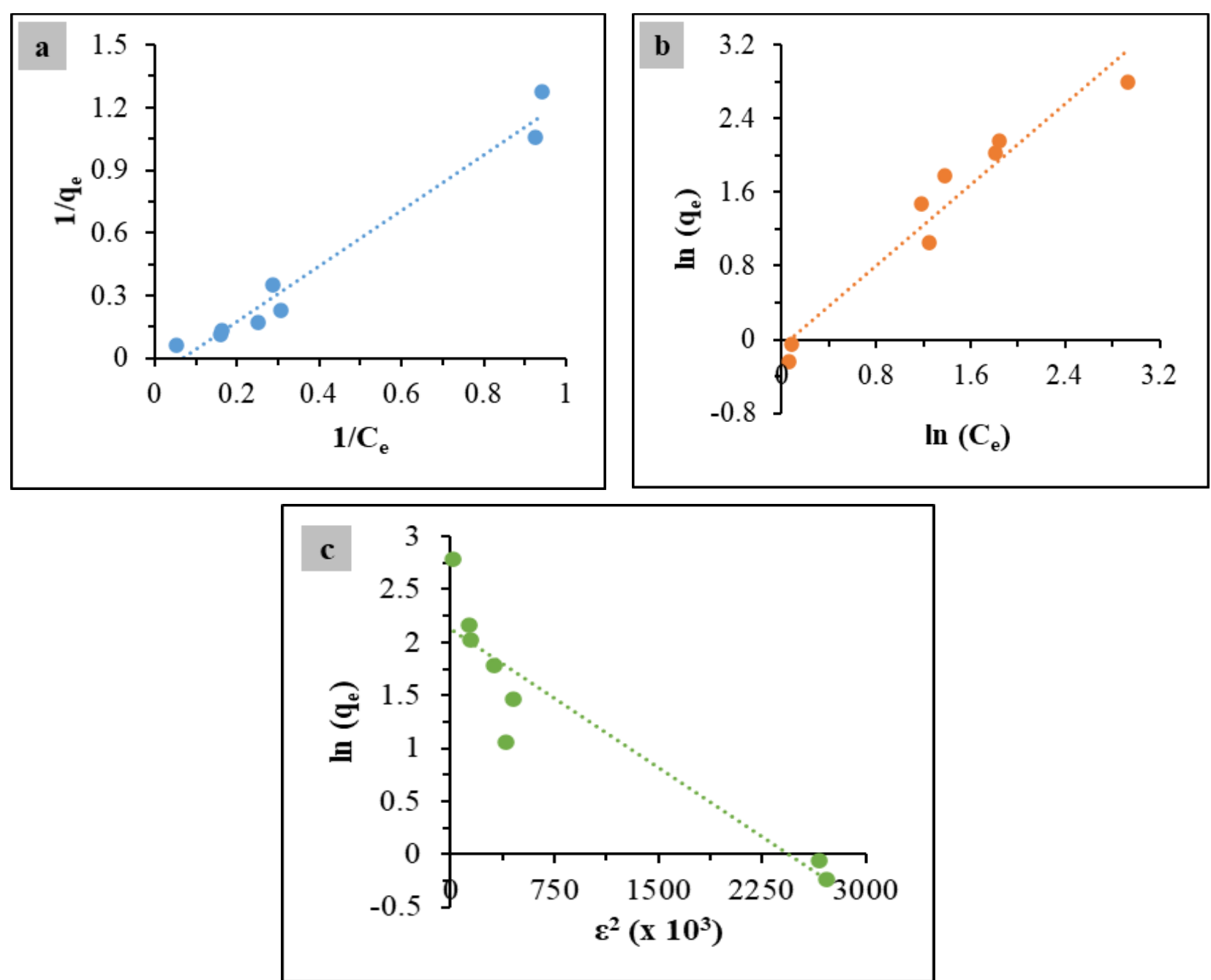

Figure 7. Linearity plot of adsorption isotherm copper (II) ions by eggshells powder (a) Langmuir, (b) Freundlich, (c) Dubinin-Radushkevich 


\section{Adsorption isotherms}

Basic assumption of adsorption is the interaction between adsorbate and adsorbent surface. Adsorption isotherm provides information about the equilibrium constant and mechanism of adsorption process, which can be used to establish an effective design of adsorption system (Tan, Ahmad, \& Hameed, 2009; Foo and Hameed, 2010; Makeswari and Santhi, 2013). Various adsorption isotherm such as Langmuir, Freundlich, and Dubinin-Radushkevich were tested in the present study. The reciprocal adsorption isotherm was evaluated by comparing the value of square correlation coefficient $\left(R^{2}\right)$.

\section{Freundlich isotherm}

Freundlich adsorption isotherm generally describes the adsorption process for the heterogenous active site energies sites. The linear plot of Freundlich isotherm is showed Eqs 2.

$$
\ln q_{e}=\ln K_{f}+(1 / n) \ln C e
$$

where, $q_{e}$ is the amount of copper (II) adsorbed per gram eggshell powder $\left(\mathrm{mg}^{-1}\right), C_{e}$ is the equilibrium concentration of copper (II) ion in solution $(\mathrm{mg} / \mathrm{L}), K_{f}$ is the Freundlich isotherm constant $(\mathrm{mg} / \mathrm{g})$ which indicate the adsorption capacity approximately, while $n$ is the adsorption intensity. If $n$ lies between 1 to 10 , this indicates a favourable sorption process. Those parameters also indicate the relative distribution of the energy and the heterogeneity of the active sites in adsorbent. If $n$ value bigger, the heterogeneity surface adsorbent is larger (Afroze and Sen, 2018; Ayawei, Ebelegi, \& Wankasi, 2017; Borhade \& Kale, 2017). Freundlich adsorption isotherm plot is shown in Figure $7 \mathrm{~b}$ with the $R^{2}$ value is 0.9408 . The adsorption intensity, $n$ value calculated with following equation and the result is less than 1 which interpreted unfavourable sorption process.

\section{Langmuir isotherm}

This isotherm model assume the surface containing finite number of active sites which has uniform energies in the surface, so the adsobate attracts strongly onto actives sites in adsorption surface. Therefore, it forms an uniform and homogenous monolayer adsorbate onto adsorbent surface and after that no further sorption take places (Borhade \& Kale, 2017; Tizo et al., 2018). The equation is presented in Eqs. 3 and its linearized form is shown in Eqs. 4.

$$
\begin{aligned}
& \boldsymbol{q}_{\boldsymbol{e}}=\frac{K_{L} q_{m} C_{e}}{1+K_{L} C_{e}} \\
& 1 / q_{\mathrm{e}}=1 / q_{m}+\left(1 / C_{e}\right)\left(1 / K_{L} \cdot q_{m}\right)
\end{aligned}
$$

where, $q_{e}$ is the amount of copper (II) adsorbed per gram eggshell powder $(\mathrm{mg} / \mathrm{g}), C_{0}$ and $C_{e}$ is the initial and equilibrium concentration of copper (II) ion in solution $(\mathrm{mg} / \mathrm{L}), \mathrm{q}_{\mathrm{m}}$ is the maximum monolayer coverage capacity $(\mathrm{mg} / \mathrm{g}), K_{L}$ is the Langmuir isotherm constant $(\mathrm{L} / \mathrm{mg})$. The value of $\mathrm{K}$ and $\mathrm{qm}$ were calculated from slope and intercept of plot $1 /$ qe versus $1 / \mathrm{Ce}$ (Tizo et al., 2018)
Figure 7a depicted Langmuir plot for adsorption of copper (II) ion by eggshells powder with the $R^{2}$ value is 0.9728 . The $\mathrm{q}_{\mathrm{m}}$ indicates maximum monolayer coverage capacity. From the result obtained, the calculated maximum monolayer coverage capacity were $11.01 \mathrm{mg} \cdot \mathrm{g}^{-1}$. The characteristic of Langmuir isotherm could be observed from non dimentional parameter, $R_{L}$ value which calculated using Eqs. 5.

$$
R_{L}=\frac{1}{1+K_{L} C_{0}}
$$

Unfavourable adsorption obtains when the $R_{L}$ value $>1$, while the favourable adsorption occurs when the $R_{L}$ value between 0 and 1 . If the $R_{L}$ value $=0$, indicates the irreversible adsorption (Ayawei et al., 2017). The result obtained $R_{L}$ value is 0.10 . It indicates the adsorption process copper (II) with eggshells in this study is favourable.

\section{Dubinin-Radushkevich isotherm}

This adsorption isotherm model is widely known to describe the adsorption mechanism in high heterogeneity adsorbent surface. This adsorption model is utilized frequently to determine the type of interaction that occur in adsorption process, especially heavy metals adsorption (Israel and Eduok, 2012). The Dubinin-Radushkevich linearity plot and free mean energy equation is shown in Eqs. 6 and Eqs. 7, respectively.

$$
\begin{aligned}
& \ln q_{e}=\ln q_{m}-\beta \varepsilon^{2} \\
& E=\frac{1}{\sqrt{2 \beta}}
\end{aligned}
$$

where, $\mathrm{q}_{\mathrm{e}}$ is the amount of copper (II) adsorbed per gram eggshell powder $(\mathrm{mg} / \mathrm{g}), q_{m}$ is the maximum monolayer coverage capacity $(\mathrm{mg} / \mathrm{g}), \boldsymbol{\varepsilon}$ is Polanyi potential (mol/J), $\boldsymbol{\beta}$ is Dubinin-Radushkevich constant, $E$ denotes a free mean energy $(\mathrm{J} / \mathrm{mol})$.

Physisorption mechanism occur when the $E$ value is less than $8 \mathrm{~kJ} / \mathrm{mol}$, while its value lies between 8 $\mathrm{kJ} / \mathrm{mol}$ to $16 \mathrm{~kJ} / \mathrm{mol}$, the sorption is dominated by ionexchange mechanism and the range value of $E$ is 20 $\mathrm{kJ} / \mathrm{mol}$ to $40 \mathrm{~kJ} / \mathrm{mol}$ follows chemisorption (Kumar et al., 2011). Based on the experimental data, the calculated $E$ value is $0.74 \mathrm{~kJ}$ at $298.6 \mathrm{~K}$, which exhibits the copper (II) ions adsorption in eggshell surface after alkaline solution activated was dominated by electrostatic attraction and physisorption interaction. The value of all adsorption isotherm parameters were summarized in Table 1.

Based on the value of square of correlation coefficient, $R^{2}$ between three adsorption isotherm model shown that the Langmuir isotherm model gives the best linearity and it confirms that adsorption copper(II) mechanism is driven by monolayer adsorption and electrostatic interaction occurs between adsorbed copper (II) particles and activated eggshells surface (de Lima, Nascimento, de Sousa, Filho \& Oliveira, 2012). The prior researches for eggshell used for adsorbent showed in Table 2. 
Table 1. Langmuir and Freundlich adsorption isotherm parameters for copper (II) ions removal by eggshells powder

\begin{tabular}{|c|c|c|c|c|c|c|c|c|c|}
\hline \multicolumn{3}{|c|}{ Langmuir } & \multicolumn{4}{|c|}{ Freundlich } & \multicolumn{3}{|c|}{ Dubinin Raduskevich } \\
\hline $\begin{array}{l}q_{m} \\
(m g / g)\end{array}$ & $\begin{array}{l}K_{L} \\
(L / m g)\end{array}$ & $R_{L}$ & $R^{2}$ & $n$ & $\begin{array}{l}K_{F} \\
(\mathrm{mg} / \mathrm{g})\end{array}$ & $R^{2}$ & $\begin{array}{l}q_{m} \\
(\mathrm{mg} / \mathrm{g})\end{array}$ & $\begin{array}{l}E \\
(k J)\end{array}$ & $R^{2}$ \\
\hline 11.01 & 0.07 & 0.10 & 0.9728 & 0.91 & 0.93 & 0.9408 & 8.30 & 0.74 & 0.8608 \\
\hline
\end{tabular}

Table 2. Some research related utilizing eggshell for polluted material removal

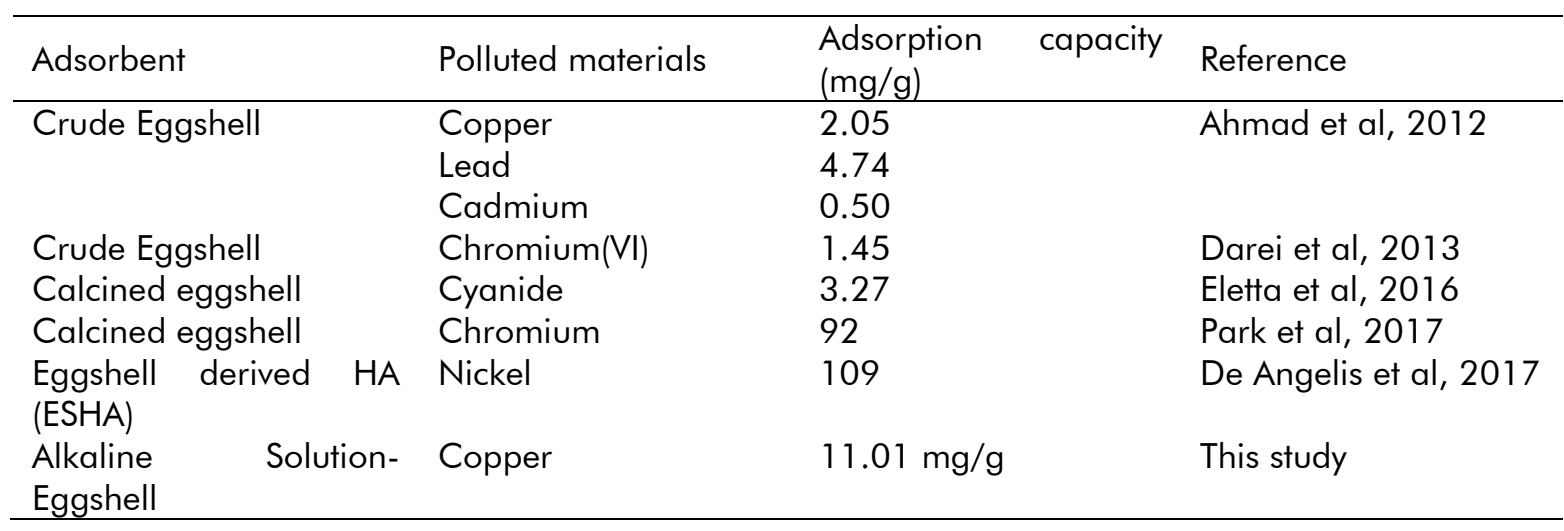

\section{Kinetic study}

Adsorption process consist of three main steps. First step is mass transfer of adsorbate from bulk solution to the external surface of adsorbent, followed by the intra diffusion process to the active site and the last is adsorption itself. Adsorption process is a reversible mechanism, When the equilibrium state is achieved, adsorption and desorption rate are equal and make adsorbate concentration in the first medium (aqueous solution) and second medium (adsorbent) is also equal. Various methods have been used to determine the kinetics of adsorption either batch system or finite bath method. In the present paper, pseudo-first order and pseudo-second order were used to investigate the kinetic of adsorption copper (II) ion by eggshells powder. The pseudo-first order assumed adsorption only occur on localized sites and involved no interaction between copper (II) ions. Maximum adsorption capacity related to the monolayer adsorbate onto active sites in adsorbent surface. The linear formed equation this kinetic model was showed in Eqs. 8.

$$
\log \left(q_{e}-q_{t}\right)=\log q_{e}-\left(k_{1} / 2.303\right) t \quad \text { (8) }
$$

where, $q_{+}$is the amount of copper (II) ion at t time $(\mathrm{mg} / \mathrm{g}), k_{1}$ is rate constant $\left(\mathrm{min}^{-1}\right)$ which were calculated from intercept the equation. The pseudosecond order model indicated adsorption capacity was proportional with the number of active sites in adsorbent surface (Eletta et al., 2016). Linear form of pseudo-second order was expressed as Eqs, 9.

$$
t / q_{t}=t / q_{e}+1 /\left(k_{2} \cdot q_{\mathrm{e}}{ }^{2}\right)
$$

where, $k_{2}$ is rate constant for pseudo-second order which calculated from the intercept of the plot regression.
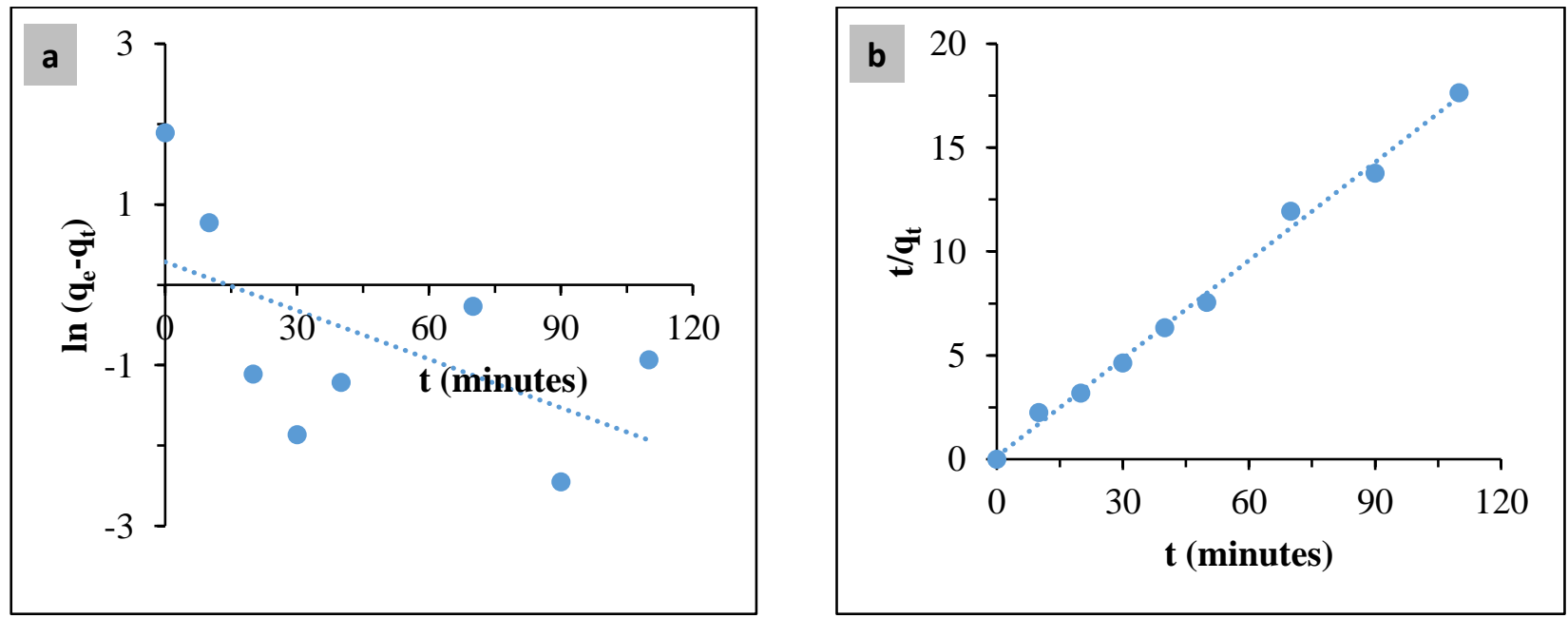

Figure 8. Kinetic modelling linear plot for adsorption copper (II) ions by eggshells, (a) pseudo-first order; (b) pseudo-second order 
Table 3. Kinetics parameter value for pseudo-first order and pseudo-second order model

\begin{tabular}{|c|c|c|c|c|c|c|c|c|}
\hline \multirow[b]{2}{*}{ Metal lons } & \multicolumn{4}{|c|}{ Pseudo-first order } & \multicolumn{4}{|c|}{ Pseudo-second order } \\
\hline & $\begin{array}{l}k_{1} \\
(1 / \min )\end{array}$ & $\begin{array}{l}q_{e(\text { calc) }} \\
(\mathrm{mg} / \mathrm{g})\end{array}$ & $\begin{array}{l}q_{e} \text { (actual) } \\
(\mathrm{mg} / \mathrm{g})\end{array}$ & $R^{2}$ & $\begin{array}{l}k_{2} \\
(\mathrm{~g} / \mathrm{mg} \cdot \mathrm{min})\end{array}$ & $\begin{array}{l}\mathrm{q}_{\mathrm{e} \text { (calc) }} \\
(\mathrm{mg} / \mathrm{g})\end{array}$ & $\begin{array}{l}q_{e} \text { (actual) } \\
(\mathrm{mg} / \mathrm{g})\end{array}$ & $R^{2}$ \\
\hline Copper (II) & 0.042 & 1.018 & 4.826 & 0.3197 & 0.516 & 4.824 & 4.826 & 0.9944 \\
\hline
\end{tabular}

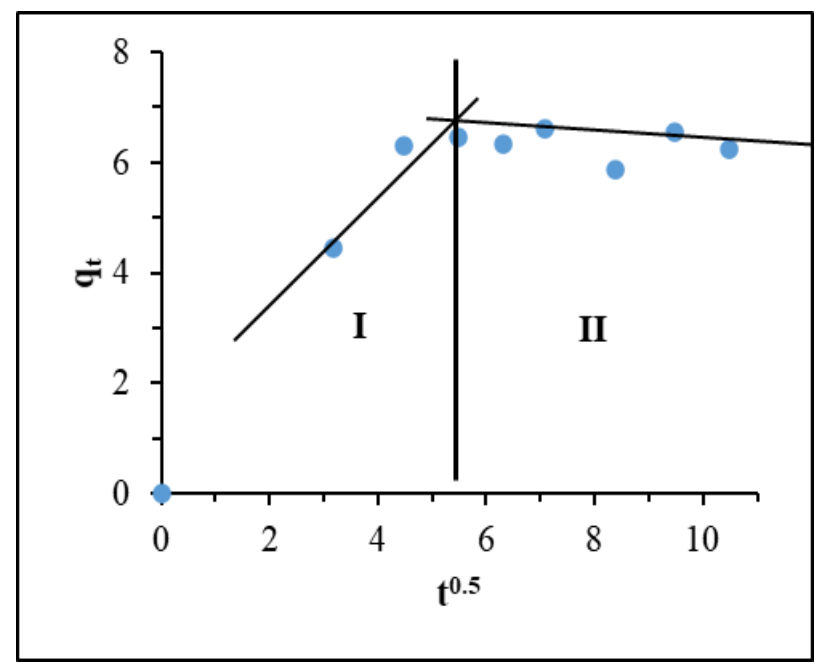

Figure 9. Plot for intra-particles diffusion in eggshells powder

The linearity plot of pseudo-first order and pseudosecond order was illustrated in Figure 8 . The values of all parameters were calculated and summarized in Table 3. The result was shown that there is no significant difference between the actual amount and calculated value of copper (II) adsorbed on the surface of the eggshells determined by pseudo-second order model. Furthermore, $R^{2}$ value for pseudo-second order closed to 1 indicated that adsorption kinetics of copper (II) ions by eggshells powder fit to the pseudosecond order model. The number of active sites in eggshells surface is proportional to adsorption capacity of copper (II) ions.

Generally, adsorbate particles moved from bulk concentration on solution to adsorbent surface through intra-particles diffusion step. This step may be the slowest step in overall adsorption process (Kaczala, Marques, \& Hogland, 2009). The rate intraparticles diffusion equation can be searched by using Weber-Morris equation (Eqs. 10).

$$
q_{t}=k_{\text {id }} . t^{0.5}
$$

where, $q_{t}$ is the amount of adsorbate at $t$ time $(\mathrm{mg} / \mathrm{g})$ and $k_{i d}$ is the rate constant for intra-particle diffusion. The $k_{i d}$ value can be calculated from slope the plot $q_{t}$ versus $t^{0.5}$. According to Eqs 9, a straight line shows the kinetic process follows the intraparticle diffusion, but the figure (Figure 9) showed multi linear plots, divided to two separated area: the first linear line (phase I) and the second linear line (phase II). In phase I, copper (II) ion adsorption controlled by surface diffusion process from bulk to the most readily eggshell active sites. Phase II depicted copper (II) ion pore diffusion from surface sites to the inner pores. The multi linear plot proved the intraparticle diffusion was not rate controlling step solely in this research (Bhatnagar et al., 2010).

\section{CONCLUSIONS}

The result of characterization with XRD, FT-IR, and SEM shows chemically activated eggshell can improve the copper (II) ions removal from water content. Major composition of eggshells is $\mathrm{CaCO}_{3}$ and slightly organic matter which have important role in the adsorption process. The optimum condition can be achieved when $0.7 \mathrm{~g}$ eggshells powder was added into $50 \mathrm{mg} / \mathrm{L}$ copper (II) solution and shaken for 50 minutes. In the present paper, adsorption of copper (II) by eggshells obeys Langmuir isotherm adsorption $\left(R^{2}\right.$ $=0.9728$ ). It assumes monolayer copper (II) ion forms onto active sites in the outer surface eggshell. The number of active sites in eggshells surface is proportional to adsorption capacity of copper (II) ions. It is proved with the kinetic measurement demonstrated that copper (II) ions adsorption process complies with to pseudo-second order rate model with the rate constant of $0.516 \mathrm{~g} / \mathrm{mg} \cdot \mathrm{min}$.

\section{ACKNOWLEDGEMENTS}

The author would like to thank to Politeknik AKA Bogor for financial support of this research, and The Integrated Laboratory Politeknik AKA Bogor (LU-AKA Bogor) for instrumental support of this research. 


\section{REFERENCES}

Afroze, S., \& Sen, T. K. (2018). A review on heavy metal ions and dye adsorption from water by agricultural solid waste adsorbents. Water, Air, \& Soil Pollution, 229, 225-275

Ahmad, M., Usman, A. R. A., Lee, S. S., Kim, S. C., \& Joo, J. H. (2012). Eggshells and coral wastes as low cost sorbents for removal of $\mathrm{Pb}^{2+}, \mathrm{Cd}^{2+}$ and $\mathrm{Cu}^{2+}$ from aqueous solutions. Journal of Industrial and Engineering Chemistry, 18 (1), 198-204

Alemayehu, E., \& Lennartz, B. (2010). Adsorptive removal of nickel from water using volcanic rocks. Applied Geochemistry, 25 (10), 1596 1602

Ayawei, N., Ebelegi, A. N., \& Wankasi, D. (2017). Modelling and intrepretation of adsorption isotherm. Journal of Chemistry, 2017, 1-11

Bade, R., \& Lee, S. H. (2011). A review of studies on micellar enhanced ultrafiltration for heavy metals removal from wastewater. Journal of Water Sustainability, 1 (1) 85-102

Bhatnagar, A., Minocha, A. K., \& Sillanpaa, M. (2010). Adsorptive removal of cobalt from aqueous solution by utilizing lemon peel as biosorbent. Biochemical Engineering Journal, 48, 181-186

Borhade, A. V., \& Kale, A. S. (2017). Calcined eggshell as a cost effective material for removal of dyes from aqueous solution. Applied Water Science, 7, 4255-4268

Carvalho, J., Araujo, J., \& Castro, F. (2011). Alternative low-cost adsorbent for water and wastewater decontamination derived from eggshell waste: an overview. Waste and Biomass Valorization, 2, 157-167

Daraei, H., Mittal, A., Noorisepehr, M., \& Mittal, J. (2015). Separation on chromium from water sample using eggshell powder as a low-cost sorbent: kinetic and thermodynamic studies. Desalination and Water Treatment, 53 (1), 214 220

de Lima, A. C. A., Nascimento, R. F., de Sousa, F. F., Filho, J. M., \& Oliveira, A. C., (2012). Modified coconut shell fibers: A green and economical sorbent for the removal of anions from aqueous solutions. Chemical Engineering Journal, 185186, 274-284

Eletta, O. A. A., Ajayi, O. A., Ogunleye, O. O., \& Akpan, I. C. (2016). Adsorption of cyanide from aqueous solution using calcinated eggshells: Equilibrium and optimisation studies. Journal of Environmental Chemical Engineering, 4 (1), 1367-1375

Foo, K. Y., \& Hameed, B. H. (2010). Insight into the modelling of adsorption isotherm systems. Chemical Engineering Journal, 156 (1), 2-10
Fu, F., Wang, Q. (2011). Removal of heavy metal ions from wastewaters: A review. Journal of Environmental Management, 92 (3), 407-418

Gollakota, A.R.K., Volli, V., \& Shu, C-M. (2019). Transesterification of waste cooking oil using pyrolysis residue supported eggshell catalyst. Science of The Total Environment. 661, 316325

Israel, U., Eduok, U. M. (2012). Biosorption of zinc from aqueous solution using coconut (Cocos nuciferal) coir dust. Achieves of Applied Science Research. 4 (2), 809-819

Kaczala, F., Marques, M., \& Hogland, W. (2009). Lead and vanadium removal from a real industrial wastewater by gravitational settling/sedimentation and sorption onto Pinus sylvestris sawdust. Bioresorce Technology, 100 (1), 235-243

Kristianto, H., Daulay, N., \& Arie, A.A. (2019). Adsorption of $\mathrm{Ni}$ (II) lon onto Calcined Eggshells: A Study of Equilibrium Adsorption Isotherm. Indonesian Journal of Chemistry. 19 (1) 143-150

Kumar, P. S., Ramalingam, S., Kirupha, S. D., Murugesan, A., Vidyadevi, T., Sivanesan, S. (2011). Adsorption behavior of nickel(II) onto cashew nut shell: Equilibrium, thermodynamics, kinetics, mechannism and process design. Chemical Engineering Journal. 167 (1), 122131

Liao, D., Zheng, W., Li, X., Yang, Q., Yue, X., \& Guo, L. (2010). Removal of lead(II) from aqueous solutions using carbonate hydroxypatite extracted from eggshell waste. Journal of Hazardous Material, 177 (1-3), 126-130

Makeswari, M., \& Santhi, T. (2013). Removal of malachite green dye from aqueous solutions onto microwave assisted zinc chloride chemical activated epicarp of Ricinus communis. Journal of Water Resources and Protection, 5 (2), 222238

The Ministry of Environment. (2014). Peraturan Menteri Lingkungan Hidup Republik Indonesia Nomor 5 Tahun 2014 Tentang Baku Mutu Air Limbah. Jakarta

Oliveira, D. A., Benelli, P., \& Amante, E. R. (2013). A literature review on adding value to solid residues: egg shells. Journal of Cleaner Production, 46, 42-47

Park, H. J., Jeong, S. W., Yang, J. K., Kim, B. G., \& Lee, S. M. (2007). Removal of heavy metals using waste eggshell. Journal of Environmental Sciences, 19 (12), 1436-1441

Semeriian, L. (2018). Removal of heavy metals (Cu, $\mathrm{Pb}$ ) from aqueous solutions using pine (Pinus halepensis) sawdust: Equilibrium, kinetic, and thermodynamic studies. Environmental Technology \& Innovation, 12, 91-103 
Setiawan, B. D., Rizqi, O., Brilianti, N. F., \& Wasito, H. (2018). Nanoporous of waste avian eggshell to reduce heavy metal and acidity in water. Sustainable Chemistry and Pharmacy, 10, 163167

Simate, G.S. \& Ndlovu, S. (2014). Acid mine drainage challenges and opportunities. Journal of Environmental Chemical Engineering, 2 (3) 1785-1803

Subbaredy, Y. Jeseentharani, V., Jayakumar, C.,Nagaraja, K. S., \& Jeyarai, B. (2012). Adsorptive removal of malachite green (oxalate) by low cost adsorbent. Journal of Environmental Research and Development, 7 (1A), 275-284

Tan, I. A. W., Ahmad, A. L., \& Hameed, B. H. (2009). Adsorption isotherm, kinetics, thermodynamics and desorption studies of 2,4,6-trichlorophenol on oil palm empty fruit bunch-based activated carbon. Journal of Hazardous Material, 164 (23), 473-482

Tang, J., Li, Y., Wang, X., \& Daroch, M. (2017). Effective adsorption of aqueous $\mathrm{Pb}^{2+}$ by dried biomass of Landoltia punctata and Spirodela polyrhiza. Journal of Cleaner Production, 145, 25-34

Tizo, M.S., Blanco, L.A.V., Cagas, A.C.Q., Cruz, B.R.B.D., Encoy, J.C., Gunting, J.V., Arazo, R.O., \& Mabayo, V.I.F. (2018). Efficiency of calcium carbonate from eggshells as an adsorbent for cadmium removal in aqueous solution. Sustainable Environment Research. 28 (6), 326-332

Yeddou, N., \& Bensmaili, A. (2007). Equilibrium and kinetic modelling of iron adsorption by eggshells in batch system: effect of temperature. Desalination, 206 (1-3), 127-134 